\title{
Resonant vibrations resulting from the re-engineering of a constant-speed 2-bladed turbine to a variable-speed 3-bladed turbine
}

\author{
Paul A. Fleming* Alan D. Wright ${ }^{\dagger}$ and Lee J. Fingersh ${ }^{\dagger}$ \\ National Wind Technology Center, National Renewable Energy Laboratory, Golden, Colorado \\ Jan-Willem van Wingerden ${ }^{\ddagger}$ \\ Delft University of Technology, Delft, The Netherlands
}

\begin{abstract}
The CART3 (Controls Advanced Research Turbine, 3-bladed) at the National Wind Technology Center has recently been converted from a 2-bladed constant speed machine to a 3-bladed variable speed machine designed specifically for controls research. The purpose of this conversion was to develop an advanced controls field-testing platform which has the more typical 3-bladed configuration. A result of this conversion was the emergence of several resonant vibrations, some of which initially prevented operation of the turbine until they could be explained and resolved. In this paper, the investigations into these vibrations are presented as "lessons-learned". Additionally, a frequency-domain technique called waterfall plotting is discussed and its usefulness in this research is illustrated.
\end{abstract}

\section{Introduction}

Improvements made to wind turbine control systems have the potential to provide important benefits. Advanced controllers can improve power capture, add damping to structural modes, and lower fatigue loading in turbine components. Additionally, advanced controllers could be developed to take advantage of non-typical sensing capabilities such as LIDAR, or novel actuation technologies such as trailing-edge flaps. ${ }^{1,2}$ Finally, advanced control techniques might prove essential for the needs of future wind turbines and plants, for example in stabilizing floating offshore turbines, or providing ancillary grid services. ${ }^{3,4}$

Field-testing is an essential component in the design and evaluation of advanced controls for wind turbines. By field-testing, a control system is proved in real conditions on a physical turbine. This allows confidence in the adoption of a new control technique by industry that might not be afforded by simulation alone. More importantly, testing on a physical turbine often presents problems, which need to be confronted, that modeling may miss. At the National Wind Technology Center (NWTC), research into various advanced control technologies for wind turbines is ongoing and field-testing is a critical component of this research.

Field-testing of advanced controllers has thus far been accomplished at the NWTC by the CART2 (Controls Advanced Research Turbine 2-bladed). The CART2 is a 600kW Westinghouse variable-speed turbine. The CART2 has been used for field-testing techniques such as adaptive control, state-space control and independent pitch control. ${ }^{5-7}$

*Research Engineer, National Wind Technology Center (NWTC), National Renewable Energy Laboratory (NREL), 1617 Cole Blvd., Mailstop 3811, AIAA member.

†Senior Engineer, National Wind Technology Center (NWTC), National Renewable Energy Laboratory (NREL), 1617 Cole Blvd., Mailstop 3811, AIAA member.

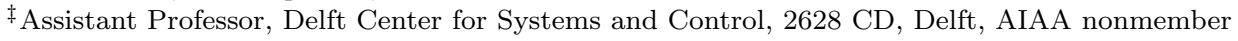




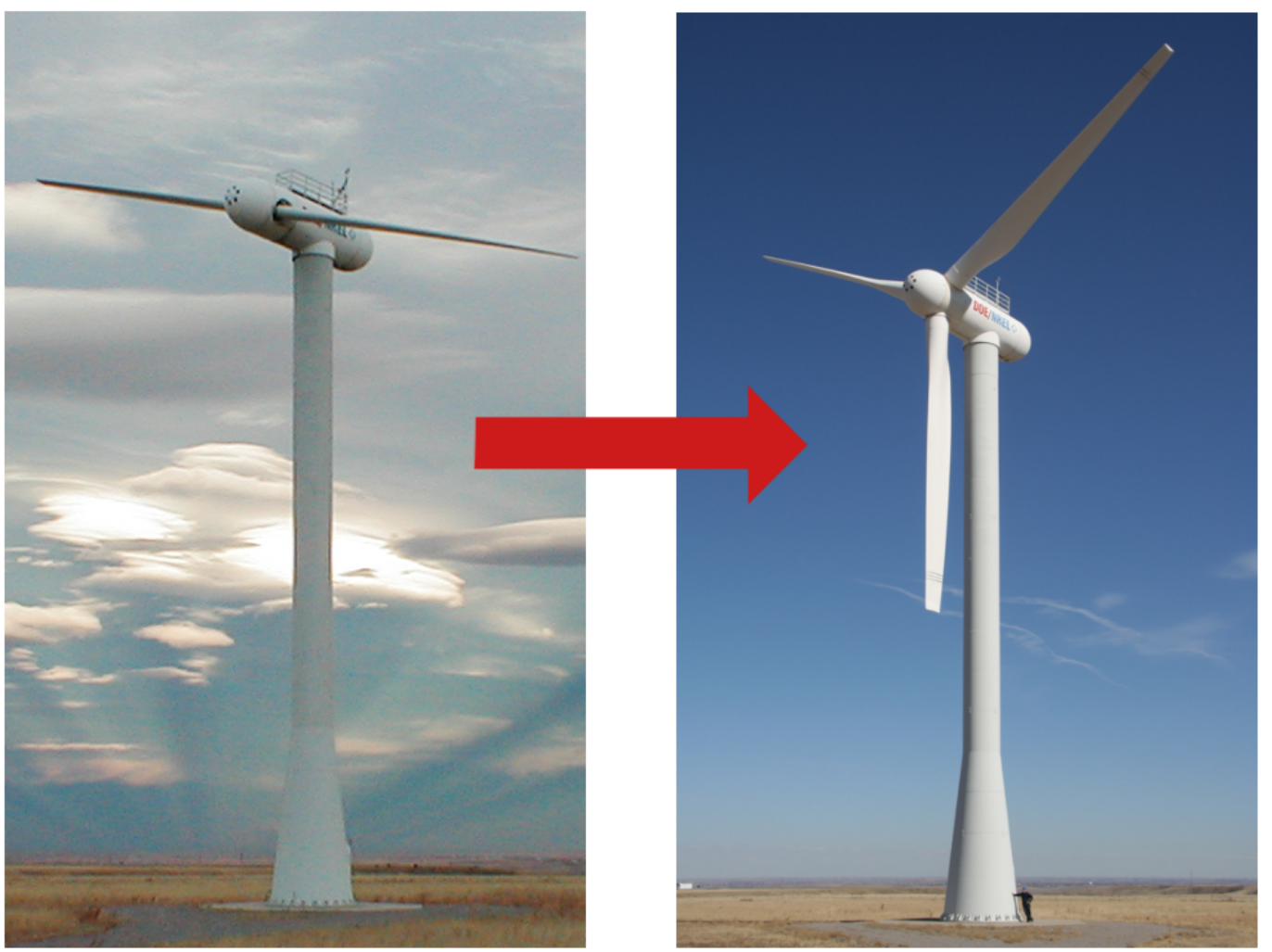

Figure 1. Converting the CART3 from a 2-bladed constant speed turbine (PIX \#18279) to a 3-bladed variable speed turbine (PIX \#18278)

Recently, a project has been performed to develop a second wind turbine control testbed: the CART3 (Controls Advanced Research Turbine 3-bladed). The CART2 and CART3 were originally identical 2-bladed turbines, but the CART3 has been converted to a 3-bladed machine. The purpose of developing a second controls turbine with the three blades was to develop a controls test-bed, with the more standard 3-bladed configuration.

\section{I.A. CART3}

In the process of developing the CART3, several modifications were made to the original turbine. First, the original 2-bladed teetering hub was replaced with a customized 3-bladed hub. The blades in the new hub are pitched using electric drives, which allow pitch rates up to $26 \mathrm{deg} / \mathrm{s}$. Additionally, the hub and blades were instrumented with encoders and strain gauges. In Figure 1, the conversion from 2-bladed to 3-bladed is shown.

In addition to the blade conversion, a new control system was devised for the CART3, which would more easily enable advanced controls development. The CART3 is expected to play a major role in future advanced controls research. Field-testing is viewed as a portion of an iterative design process that yields proven results. Controllers are developed and tested in modeling environments. When a controller has been adequately prepared in the simulated environment, it is implemented on the physical turbine for testing. If the performance does not match expectations, the controller and models are adjusted. To increase the rate of progress through this cycle, the control system has been designed to import controllers developed in varied design environments. The control system is implemented on a real time controller operating at $400 \mathrm{~Hz}$, with an assortment of sensing capabilities included. 


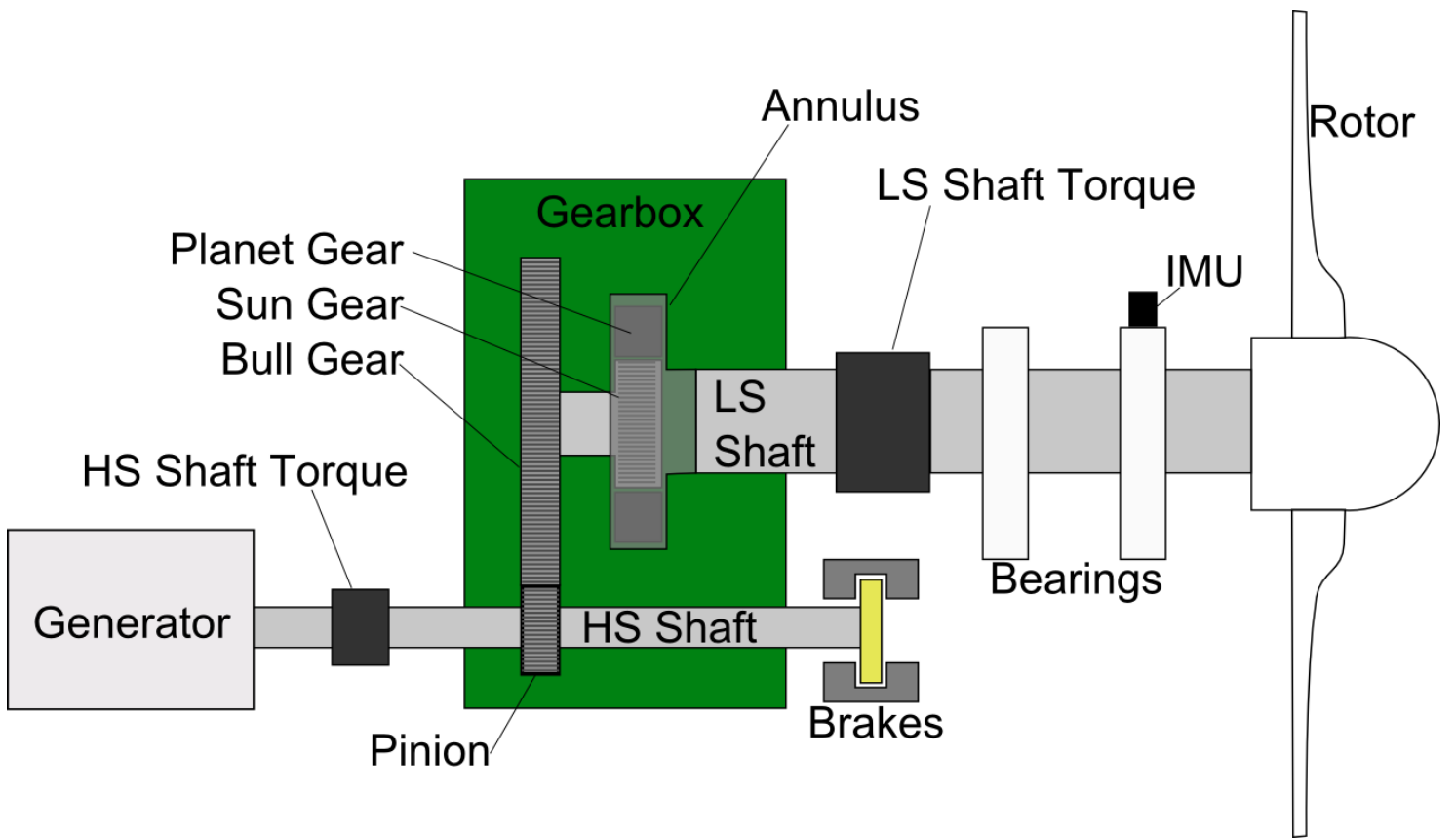

Figure 2. Schematic representation of the CART3 drivetrain. The main components of the drivetrain are illustrated along with relevant sensors (torque transducers on the HSS and LSS are shown along with the inertial measurement unit (IMU)

Additionally, although the original synchronous generator was left in place, power electronics were added to allow for torque-controlled variable speed operation. This differs from the CART2, in which the original generator was replaced with an induction generator. Finally, a large fluid coupling on the high-speed shaft was removed and replaced by a high-speed shaft torque transducer and coupling.

\section{I.B. Encountered vibrations}

After the conversion was complete and the control software had been written, a number of problems in the newly configured turbine were discovered. These problems ranged in severity and particular details, but shared some common causes. Briefly, the three newly discovered issues were:

- A $52 \mathrm{~Hz}$ oscillation measured in the torque experienced by the high-speed shaft (HSS)

- A $109 \mathrm{~Hz}$ oscillation appearing in the nacelle acceleration measured by the inertial measurement unit (IMU)

- An unstable $2.7 \mathrm{~Hz}$ drivetrain oscillation at rated speed (generator, high-speed shaft (HSS), low-speed shaft (LSS) torsion and edgewise blade bending)

The drivetrain of the CART3 is shown in Figure 2. Illustrated are the main structural components, as well as, sensors used in measuring torque levels and acceleration.

In this paper, the process of investigating and explaining these issues is documented as a "lessons-learned." In the case of the drivetrain instability, numerous possible causes were considered, and experiments were employed to test each hypothesis. Additionally, a frequency domain technique called waterfall plotting, used extensively in this work, is explained and its usefulness in the diagnosis of these types of issues is shown. 


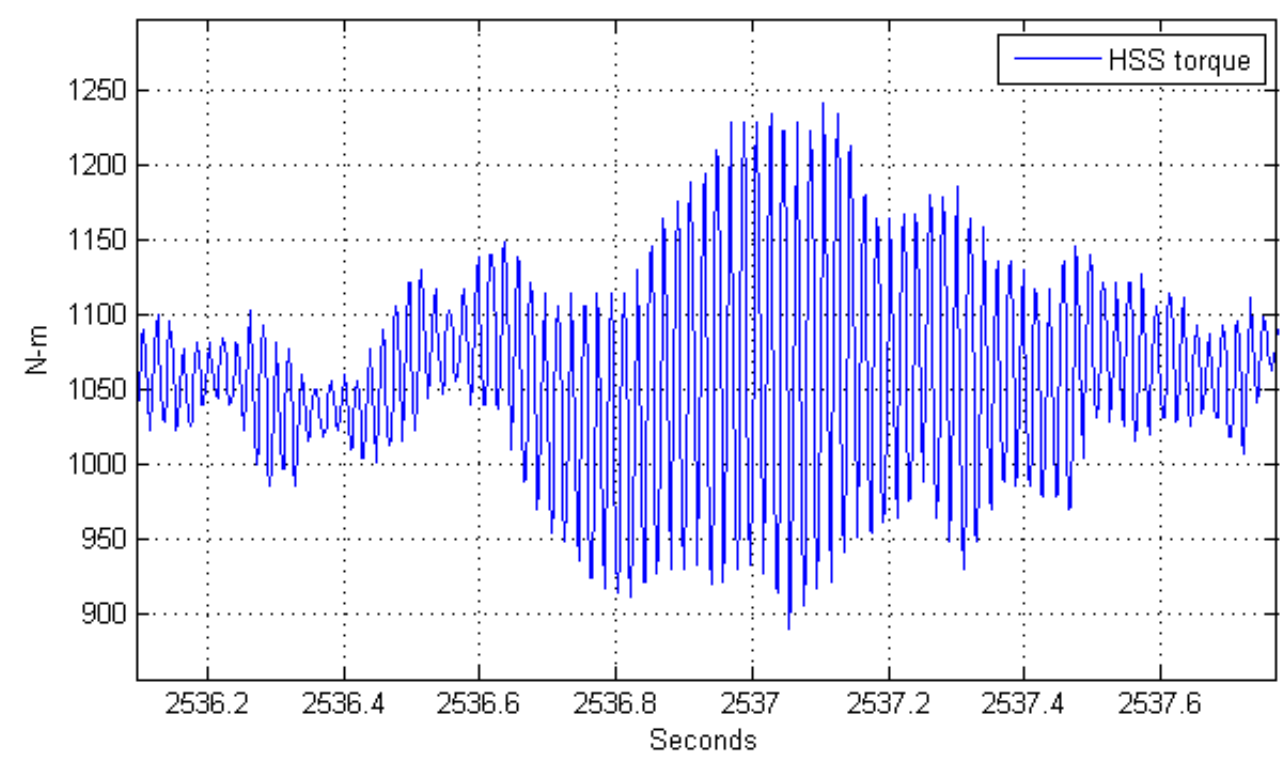

Figure 3. $52 \mathrm{~Hz}$ torque oscillation on the HSS of the CART3

\section{Waterfall plots}

In this work, waterfall plots are used to investigate and understand the observed phenomena. A waterfall in our use is a 2-dimensional surface plot. A sliding window is passed along the signal and a frequency spectrum is computed and stored for each window. In this work, the window is a Hanning window with a width of 3 - 30 seconds. In the end, each spectrum is binned according to the average low-speed shaft RPM (LSSRPM). The surface plot then shows the frequency spectrum at each rotor speed, with the magnitude of the spectrum indicated by color. The highest amplitude values are indicated with red and the lowest by blue.

To demonstrate the way in which waterfall plots are utilized, the investigation into the $52 \mathrm{~Hz}$ oscillation mentioned above is discussed. An example of this behavior is provided in Figure 3. This vibration was assumed initially to have been produced by the generator; however its occurrence when the generator was offline disproved this. Additionally the oscillation frequency did not change with rotor speed, while the amplitude did, increasing and decreasing with changes in rotor speed.

To better understand this phenomena, we began producing waterfall plots of the HSS torque signal. The waterfall plot for the high-speed shaft torque is shown in Figure 4. The waterfall plot in Figure 4 provides an illustration of how the frequency content of the torque varies with rotor speed. The results are instructive; a spike is consistently observable at $52 \mathrm{~Hz}$, but the amplitude "blooms" at rotor speeds where this frequency is coincident with another RPM-dependent oscillation. This strongly suggests a resonance at $52 \mathrm{~Hz}$, which is excited by coincident excitation frequencies.

It is possible to identify the dominant excitation frequencies as being mechanically induced. These excitation frequencies are mapped out in the right plot in Figure 4 and are identified as gear-meshing and shaft "per-revolution" frequencies. The source of these frequencies can be seen in Figure 2. Both shafts (high-speed shaft (HSS) and low-speed shaft (LSS)) produce excitation frequencies at per-revolution intervals and are sometimes call per-rev excitations and are notated $1 \mathrm{P}$ for once per-revolution, $2 \mathrm{P}$ for twice per-revolution and so on. These are typically labeled $1 \mathrm{P}$ for once-per-revolution, $2 \mathrm{P}$ for twice-per-revolution. In addition, gear meshing frequencies occur at frequencies of number of teeth times revolution speed of gear. The annulus meshing frequency would be the number of teeth on the annulus gear multiplied by the low speed shaft $1 \mathrm{P}$ frequency. 

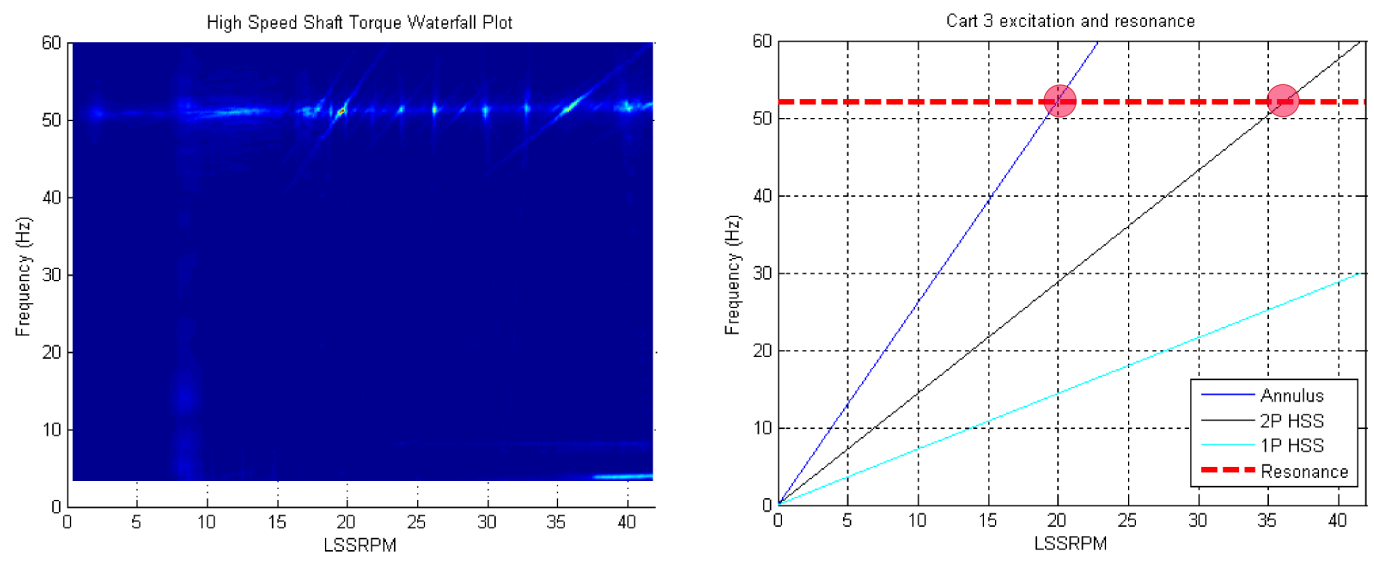

Figure 4. Comparing waterfall plot of HSS torque (left) with per-rev and gear-meshing frequencies of the CART3 (right)
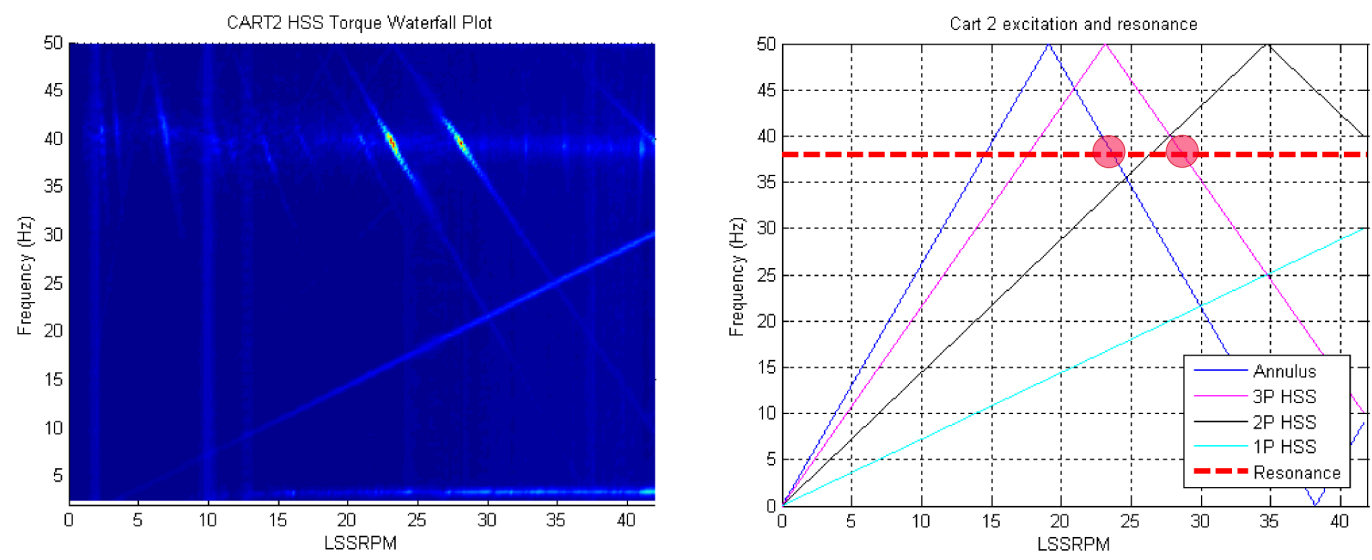

Figure 5. Comparing waterfall plot of HSS torque on the CART2 with per-rev and gear-meshing frequencies of the CART2. Note that due to nyquist reflection about $50 \mathrm{~Hz}$, the resonance at $62 \mathrm{~Hz}$ appears at $38 \mathrm{~Hz}$.

The gear meshing frequencies also produce harmonics. By comparing the waterfall plot derived from the running data with the locations of the excitation frequencies, it appears that the vibration is a structural resonance, excited predominantly by RPM-dependent excitation.

Further determination could be made through a comparison with the CART2. As mentioned earlier, the CART2 and CART3 started as identical turbines. However, the CART3 was converted to a 3-bladed turbine. In addition, on the CART2 the synchronous generator was replaced with an induction generator. Based on these changes, one would expect a resonance to exist at a higher frequency on the CART2. Rebuilding Figure 4 using CART2 data, Figure 5 indicates this is true. One thing to point out in looking at Figure 5 is that the CART2 control system samples data at $100 \mathrm{~Hz}$, which places the Nyquist frequency at $50 \mathrm{~Hz}$, and therefore, some of the excitation signals (and the resonance at $62 \mathrm{~Hz}$ ) are reflected about the Nyquist frequency.

Using waterfall plots, the HSS oscillation observed in the time domain in Figure 3 was identified. After determining the nature of the oscillation, it was decided that the oscillation was acceptably small and no further action was taken. In the remaining sections, waterfall plots are used to identify and resolve the more serious vibrations encountered. 

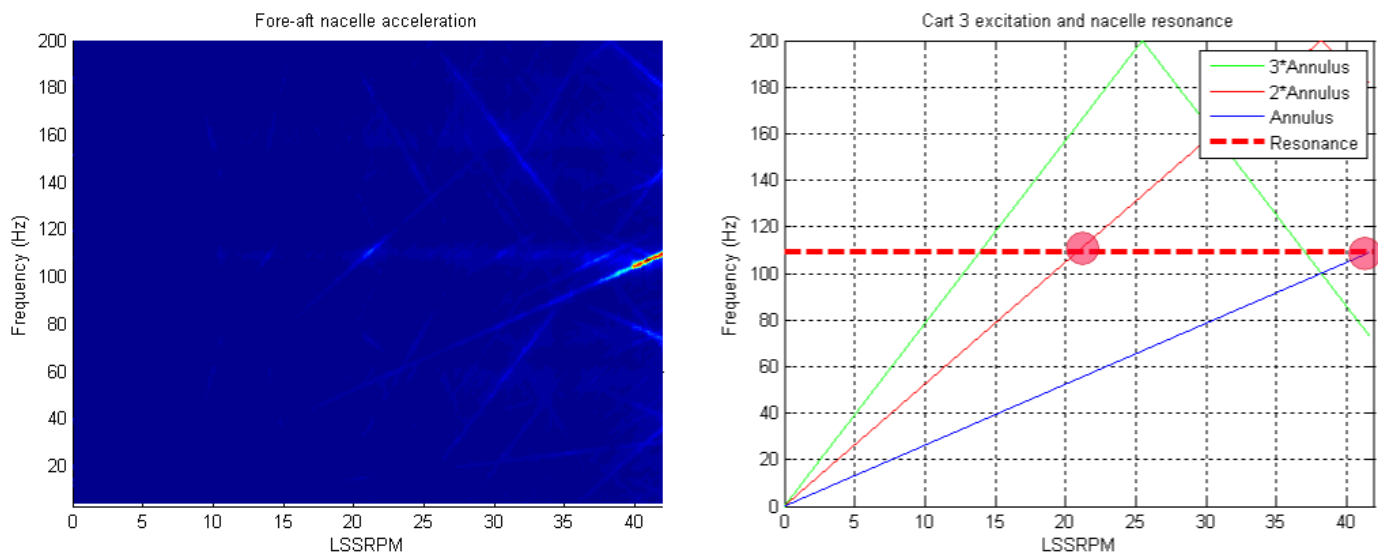

Figure 6. Comparing waterfall plot of frequency spectra of nacelle acceleration with locations of gearmeshing frequencies for CART3 (Nyquist frequency at 200Hz).

\section{Nacelle Acceleration}

A resonant vibration in the nacelle acceleration, similar to the HSS torsional vibration described above, was also discovered, and seems to be a resonance excited by coincident excitation frequencies. However, this vibration is of a more critical nature and it is large enough to trigger the SCADA system's over-acceleration fault mode on the CART3. Also, the coincidence of excitation and resonance occurred at rated rotor speed, which means that the turbine's controller speed objective causes the rotor to dwell on this overlap. Acceleration is measured on the CART3 by an inertial measurement unit (IMU) mounted to the front thrust bearing of the turbine (see Figure 2). The waterfall plot for the acceleration in the fore-aft direction, measured by the IMU, is shown in Figure 6.

Considering Figure 6, there is, as was the case on the HSS, a resonance excited by per-rev frequencies. The large oscillation around the rated speed is due to the overlap with the annulus (a stage in the gearbox) meshing frequency.

This raised the question of how changes made to the CART3 could cause this, and why was it not been observed earlier on the CART2? The answer, in a similar way to previous observations on the HSS torque signal, was there was a resonance on the CART2, but at a higher frequency. This would imply that the annulus meshing frequency never coincides with the resonance.

To determine the cause of the resonance, several extra accelerometers were placed in the CART3, along with a separate data acquisition system. This system was meant to identify the location of the resonance. By using a completely separate system, it eliminated the possibility that the oscillation could be an artifact of the IMU itself, or the data system. Referring again to Figure 2, accelerometers were placed on the front bearing, the rear bearing, the bed plate and on the gearbox. Then the CART3 was accelerated to $20 \mathrm{RPM}$ to generate the excitation signals and data was collected.

Looking at the collected data, it was discovered that although the excitation frequencies emanating from the gearbox could be observed on all components, the resonance was only observed by the IMU. This led to an important realization. Although the mounts which attach the IMU to the front bearing of the CART2 and CART3 share an identical design, the CART3's mount is made from 1/4" aluminum, while the CART2's mount is $1 / 2$ " aluminum. A second test was performed, in which an accelerometer was placed on the mounts of the CART2 and CART3 and excitation provided by tapping. This test exposed the cause of the resonance to be the thinner IMU mount of the CART3, which resonated at $109 \mathrm{~Hz}$. The CART2 IMU mount resonated at 275 $\mathrm{Hz}$. Because this higher resonance had never matched with the annulus meshing frequency, this explained why the vibration was so much more of a problem on the CART3 than on the CART2. 


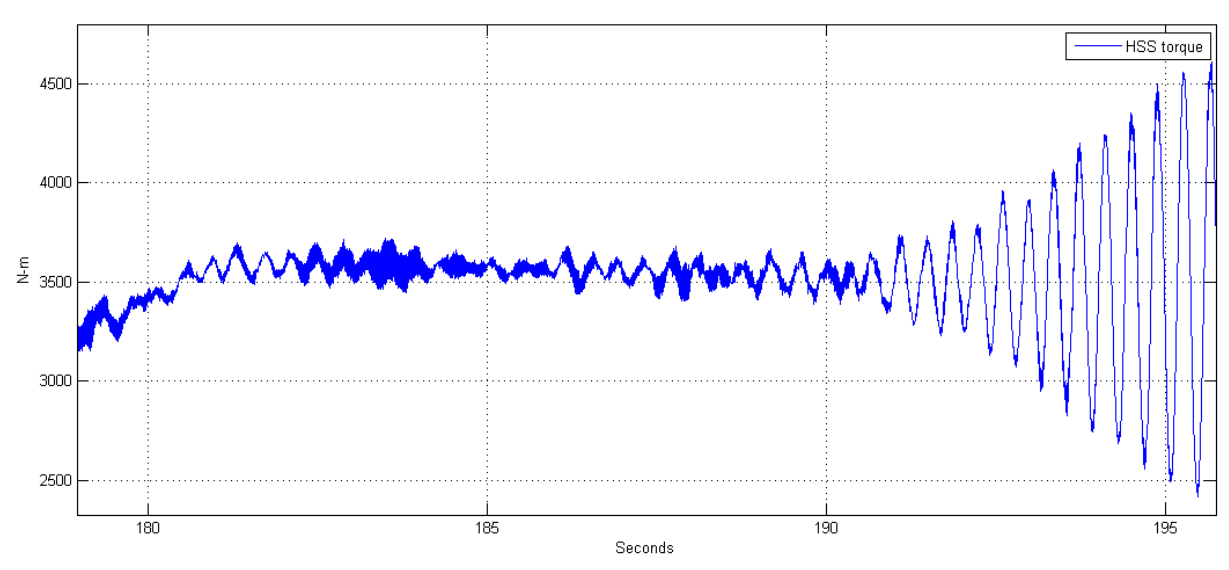

Figure 7. Collected signals from CART3 during operation at rated speed

Once located, this issue was easily resolved by stiffening the CART3 IMU mount with set-screws.

\section{Drivetrain/edwewise-bending coupled instability}

The final problematic oscillation which emerged following the re-engineering was an unstable oscillation in the drivetrain and edgewise collective bending. This oscillation can be seen looking at HSS torque collected from the CART3 during a test run shown in Figure 7.

This oscillation, as was the case for the oscillation observed in nacelle acceleration, forced the turbine to stop upon reaching rated speed. It was measured in generator torque, HSS torque, LSS torque, and collective edgewise bending (all blades bending in the same direction in the plane of rotation.) The oscillation occurred whenever rated speed was achieved, and we collected a catalog of these occurrences to study. Based on results like those shown in Figure 7, the following initial observations were reached:

- The oscillation is torsional in nature, operating on both shafts of the drivetrain and, also in the "edgewise collective" mode.

- The oscillation at $2.7 \mathrm{~Hz}$ is the first torsional mode of the drivetrain. It is always present to some extent when the turbine is operating and is always coupled with edge-wise bending. However, only at rated speed does it exhibit the behavior shown in Figure 7, where each cycle is larger than the previous.

Based on the results, it was clear that the cause of the oscillation, as in the case of the oscillation in the nacelle acceleration, needed to be resolved before the CART3 could run, since the magnitude of the oscillation precludes operation at rated speed. However, the cause of the sudden growth in the $2.7 \mathrm{~Hz}$ oscillation at rated speed could not be easily explained. Several initially plausible explanations were explored. In the following sections, each of the possibilities is examined and weighed against the evidence.

\section{IV.A. Aero-elastic instabilities}

\section{IV.A.1. Stall-induced instability}

The first cause investigated is a stall-induced instability, such as described in Lindenburg ${ }^{8}$ and also Hansen. ${ }^{9}$ This type of instability can be caused in certain circumstances when the blades have a relatively high angle of attack. There was reason to suspect that this could occur on the CART3. 
The original controller of the CART3 targeted in Region 2 a tip-speed-ratio (TSR) of 5.8, which is atypically low. The reason for this selection was that it was the true peak of the Cp-lambda table, that is, running it at this TSR should provide optimal power capture in the steady state case. However, a by-product of this control law is that Region 3 is reached at a low TSR, which could cause a stall-type instability. Additionally, the fine blade pitch angle was selected accordingly to match this TSR. It yielded a lower angle than would be necessary at other TSR choices, further tipping toward stall instability.

Observing the Cp-lambda table for the CART3, it was noticed that the surface near the peak is very flat thus a higher TSR and fine pitch angle could be chosen without a significant loss of power capture. A new TSR of 7.2 was selected and the fine pitch was raised by 0.7 degrees.

Although this change was probably beneficial, it failed to stabilize the $2.7 \mathrm{~Hz}$ oscillation at rated speed. Additionally, cases were found in which the oscillation was growing in spite of higher blade pitch angles. In the end, stall-induced instability was therefore ruled out.

\section{IV.A.2. Whirl and flapwise coupling}

Two other sources of instability were also considered. The first was that the CART3 was experiencing a sort of whirl mode. In this type of instability, the center of gravity of the hub begins to rotate and can become unstable, under some circumstances. The second is a coupling with collective flapwise blade bending.

To test these two possibilities, a plot of the model frequencies and damping was derived using non-linear models of the CART3. FAST (Fatigue, Aerodynamics, Structures, and Turbulence) is a wind turbine modeling software supported by the NWTC, which can be used to simulate wind turbines, as well as produce linearized models of turbine systems. ${ }^{10}$ A FAST model of the CART3 was developed, using known structural properties, and tuned to match the results of a modal test completed in 2009. ${ }^{11}$ This non-linear model was then linearized at a range of wind-speeds to produce a set of mode frequencies and mode damping for modes in the range of 0-10 Hz. In Figure 8, the result of this simulation is shown. The predicted modal frequencies are shown with predicted modal damping, using the various colored markers. Additionally, red-dotted lines are used to indicate the results determined by modal testing of the CART3, and to show the relative agreement between model and reality. Finally, this plot was further verified through comparison with waterfall plots of multi-blade coordinate signals, such as collective flap bending and asymmetric edgewise bending.

Observing Figure 8, it can be seen that neither the collective flap mode, nor progressive or regressive edgewise bending modes, is very close to $2.7 \mathrm{~Hz}$ at rated speed, which makes both possibilities unlikely. Therefore, both causes were removed from consideration.

\section{IV.B. Unstable control law}

Another possibility for a source of instability was the control law used in regulating turbine speed and power. The controller is a typical Region 2 - Region 3 controller. Torque control is used in Region 2 to maintain an optimal tip-speed ratio, while the blades are kept at fine pitch. Pitch control is used to regulate speed and power in Region 3, with torque kept at rated. The extra feature added to the basic control law was a slow integrator of torque error, intended to remove seasonal variations in drive torque settings without requiring recalibration. It was expected, largely because this control law is identical to that used on the CART2, that none of this would have a destabilizing effect.

After investigation, the presumption that the control law was not the problem was more or less correct. The pitch controller might contribute to the instability, but because there are cases in which the $2.7 \mathrm{~Hz}$ oscillation becomes fairly large before any pitching occurs, it is unlikely that the pitch control could be the cause. The Region 2 torque control is typically not involved because the turbine is usually in Region 3 when the instability occurs. Finally, the torque error integrator was

the most likely source of the instability problem. Since the instability still occurred when running the turbine with this feature disabled it was possible to rule this out as well. 

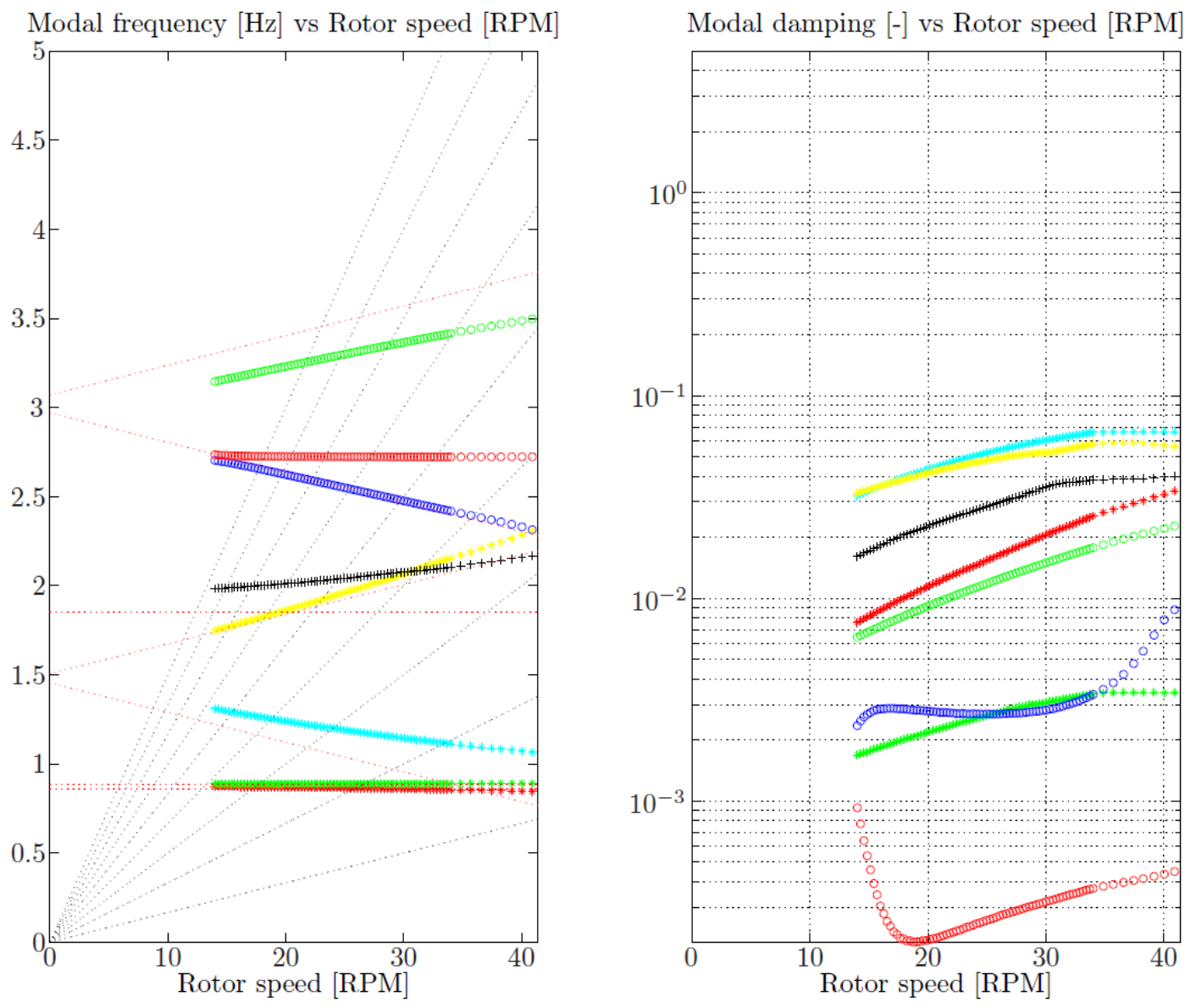

Figure 8. Eigenfrequencies and corresponding modal damping vs rotor frequency (RPM). The red dotted lines represent the predicted modes based on the modal test ${ }^{11}$ and the black dashed lines represent the 'per-rev' excitations. Black crosses indicate the flapwise collective blade bending mode. Green and blue circles indicate the edgewise blade bending asymmetric modes. The $2.7 \mathrm{~Hz}$ drivetrain/edgewise coupled mode is indicated by red circles and has the least damping. 


\section{IV.C. Negatively or very badly damped mode}

This possibility stipulates that the drivetrain edgewise collective coupled mode is very poorly damped in certain conditions. The lower damping could be related to the aerodynamics of stall, discussed earlier, and it could conceivably become negative, as discussed in Lindenbrug. ${ }^{8}$

This idea was inspected first using results shown in Figure 8, where the damping of the $2.7 \mathrm{~Hz}$ mode (red circles) is provided in the right hand plot. These damping values were computed in "worst-case," ignoring structural damping. The values provided in Figure 8 indicate that this mode is indeed poorly damped, although not negatively so. Additionally, the minimum level of drivetrain damping is predicted to occur well before rated rotor speed.

A second approach used to investigate the possibility of negative damping of the first drivetrain mode was to perform a system identification experiment to obtain the total damping of the system. A subspace identification method was used to determine a model of the drivetrain which could be used to provide an estimate of total damping. ${ }^{12}$ This experiment yielded a measured damping of approximately 0.05 at 20 RPM.

Based on the results of simulation and system-identification, it seems that the best description of the $2.7 \mathrm{~Hz}$ drivetrain mode is poorly, but not negatively, damped. Therefore, negative damping was eliminated from consideration.

\section{IV.D. Excitation and low damping}

A variant of the hypothesis, forwarded in the previous subsection, is that the drivetrain/edgewise coupled mode, while not negatively damped, is very lightly damped. A persistent excitation signal at $2.7 \mathrm{~Hz}$ could, therefore, cause the increasing oscillation at $2.7 \mathrm{~Hz}$. The difficulty for this hypothesis is in identifying the excitation, as had been done in the earlier cases of HSS torque and nacelle acceleration. A waterfall plot of shaft torque is shown in Figure 9.
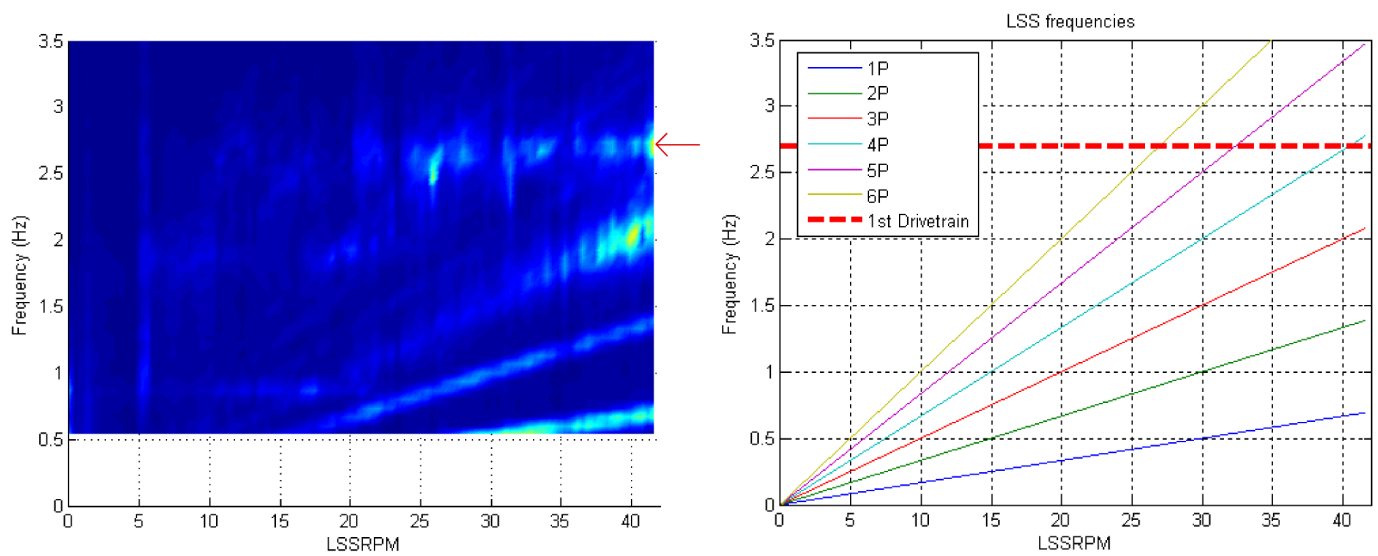

Figure 9. Waterfall plot of the low-speed shaft (LSS) torque. A small red arrow indicates the location of the large $2.7 \mathrm{~Hz}$ oscillation

A candidate excitation is clearly $4 \mathrm{P}$. Certainly this will cause some increase in the magnitude of the $2.7 \mathrm{~Hz}$ oscillation. However there are some problems with this hypothesis. First, why should $4 \mathrm{P}$ be of greater excitation than $6 \mathrm{P}$ ? In other waterfall plots, $6 \mathrm{P}$ seems to be the larger of the two excitations, and this is logical on a 3-bladed turbine. Further, 4P does not appear to have a strong physical meaning on a 3-bladed machine outside of a harmonic of $1 \mathrm{P}$.

The 4 per-rev excitation does not appear to be a direct match to the resonance at rated speed. Figure 10 is a close-up view of the waterfall plot for low-speed shaft torque near where the $2.7 \mathrm{~Hz}$ resonance intersects $4 \mathrm{P}$. It can be seen that the unstable vibration does not occur where the per-rev excitation intersects the resonance. This indicates that it is not simply a low-damped resonance driven by a per-rev excitation. 


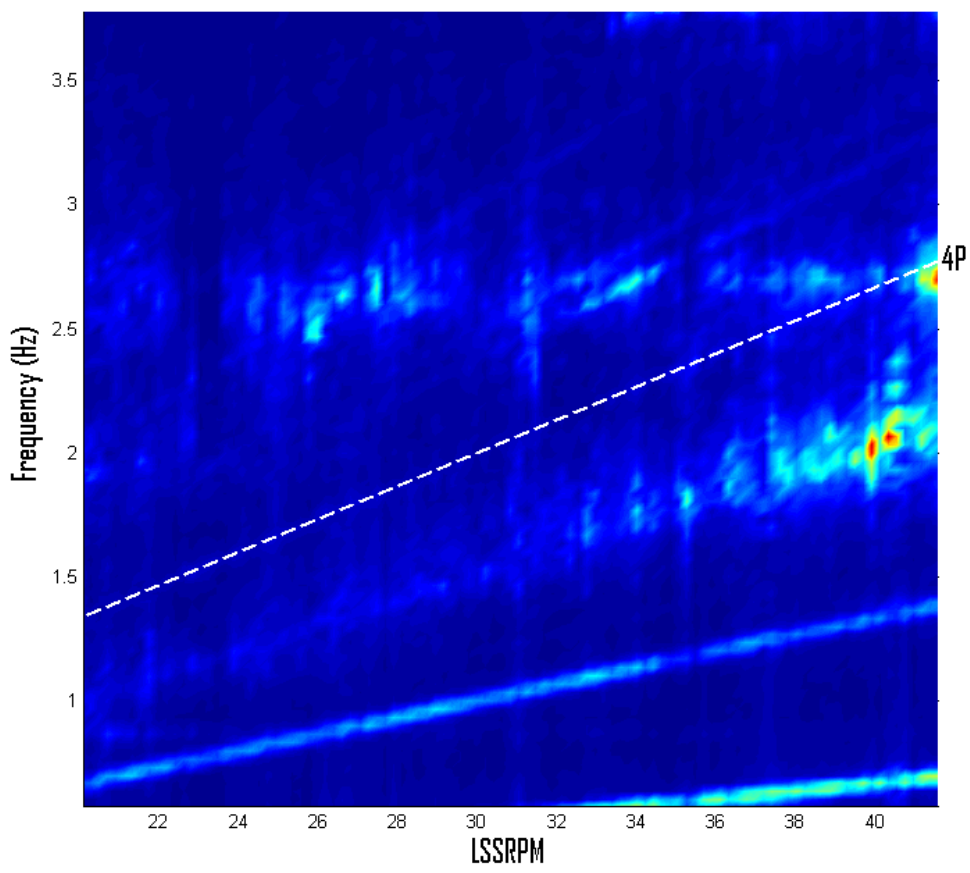

Figure 10. Zoomed in waterfall plot of low-speed shaft torque with $4 P$ excitation shown.

An experiment was performed, in which the turbine was run at rated speed, with a reduced torque applied to the generator. This succeeded in stabilizing the $2.7 \mathrm{~Hz}$ mode. It appears that the power electronics contributed to the instability because this simple adjustment stabilized the drivetrain. Low damping is almost certainly a component of the instability, and $4 \mathrm{P}$ excitation could be a part as well; however, based on these results, it seemed that the power electronics needed to be considered to explain the instability.

\section{IV.E. Power electronics}

The final area to search for an explanation for the unstable rise in the drivetrain mode is within the power electronics/generator system. The generator of the CART3 is a field-excited, synchronous generator. The power electronics (PE) connects the generator to the grid. The PE accepts a torque reference from the CART3 control system, and attempts to maintain this reference by adjusting the current applied to both the stator and the rotor of the generator.

Thus, the PE contains inner-feedback loops to maintain a requested torque level and is, therefore, capable of destabilizing a resonant mode. One might expect this to be a problem at any rotor speed and not just rated, however there are reasons why the behavior of the PE might worsen at rated speed. One reason is the proximity of the generator to its flux-weakening regime (the drive is forced to limit flux above rated speed). Another possibility is the approach of an internal limit when operating near rated speed, torque, and power.

To investigate these possibilities, diagnostic signals were recorded from the PE during operation and synchronized with SCADA data. As mentioned earlier, the CART3 runs stably at rated speed, when the torque level is reduced. Investigation of the behavior of drive signals, when running at rated speed in reduced torque, indicate that the drive undergoes a change around rated speed.

This change can be observed through a time-based waterfall plot. In a time-based waterfall plot, rather than binning against rotor speed, the spectrum is plotted against time (this is also 
called a spectrogram.) A time-based waterfall plot of signals collected with the reduced torque controller is shown in Figure 11.

\section{Flux Feedback Waterfall}

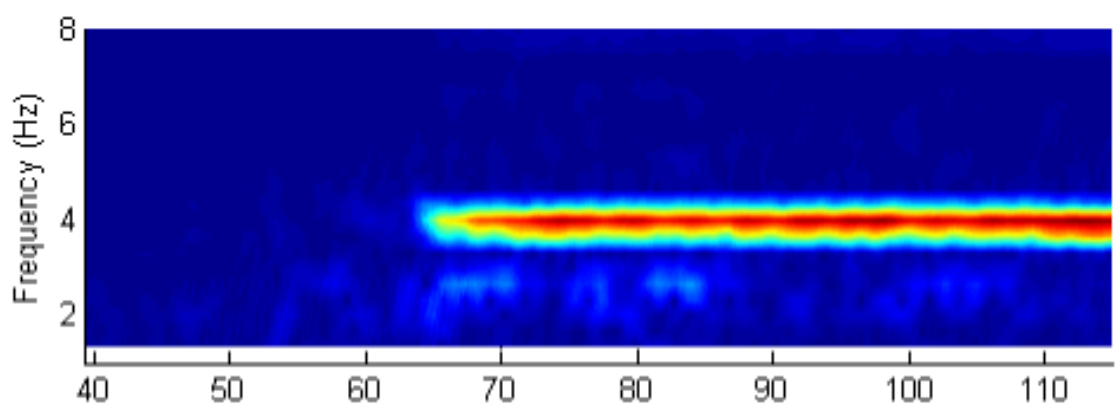

\section{LSS Torque Waterfall}
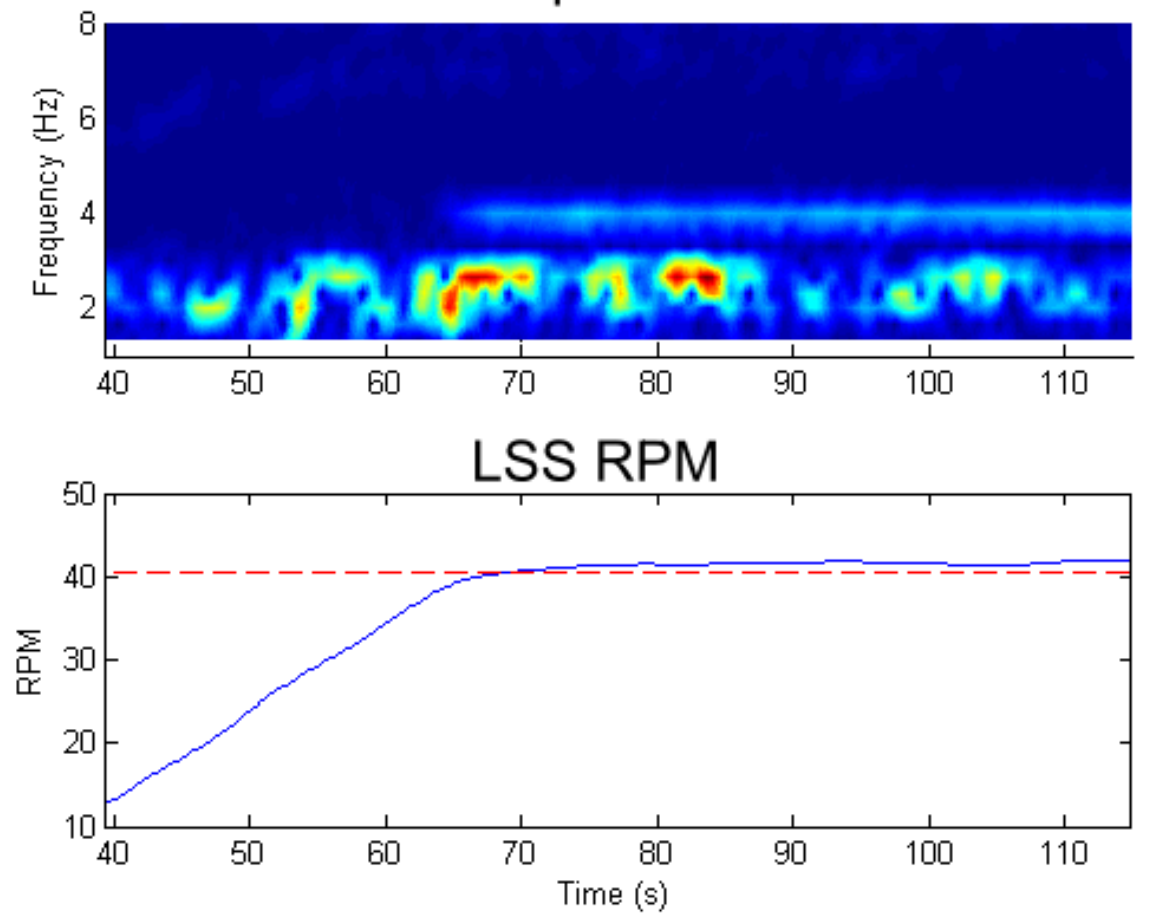

Figure 11. Time-based waterfall plots of flux feedback and LSS torque when running in reduced torque and rated speed

The top waterfall plot is the flux feedback, an internal drive measurement of generator flux. The middle figure is LSS torque and the lower plot is provided to show the rotor speed over time. Notice that when the speed crosses a certain threshold, a $4 \mathrm{~Hz}$ oscillation suddenly appears in flux. This oscillation is not a known structural mode of the wind turbine and behaves in a persistent way which is dissimilar to normal drive resonances (compared for instance with the stochastic nature of the $2.7 \mathrm{~Hz}$ oscillation in LSS torque.) This oscillation is observable in all cases when the drive approaches rated speed. Both full and reduced torque controllers show this phenomenon. In the case of the full torque controller however, after reaching rated speed, the oscillation in the flux suddenly switches from $4 \mathrm{~Hz}$ to $2.7 \mathrm{~Hz}$ and the mode destabilizes. This is taken as strong evidence that there is indeed a behavior change in the PE at near rated speed.

Based on this result, a solution to the instability is a reduction in the rated speed of the turbine 
to avoid the change in $\mathrm{PE}$ behavior. To test this hypothesis, the turbine rated speed was reduced to 37 RPM. This produced the desired result. The $4 \mathrm{~Hz}$ oscillation did not appear and the $2.7 \mathrm{~Hz}$ oscillation remained stably bounded. A power spectral density plot in Figure 12 compares the three control variations (full torque and speed, reduced torque and reduced speed.)

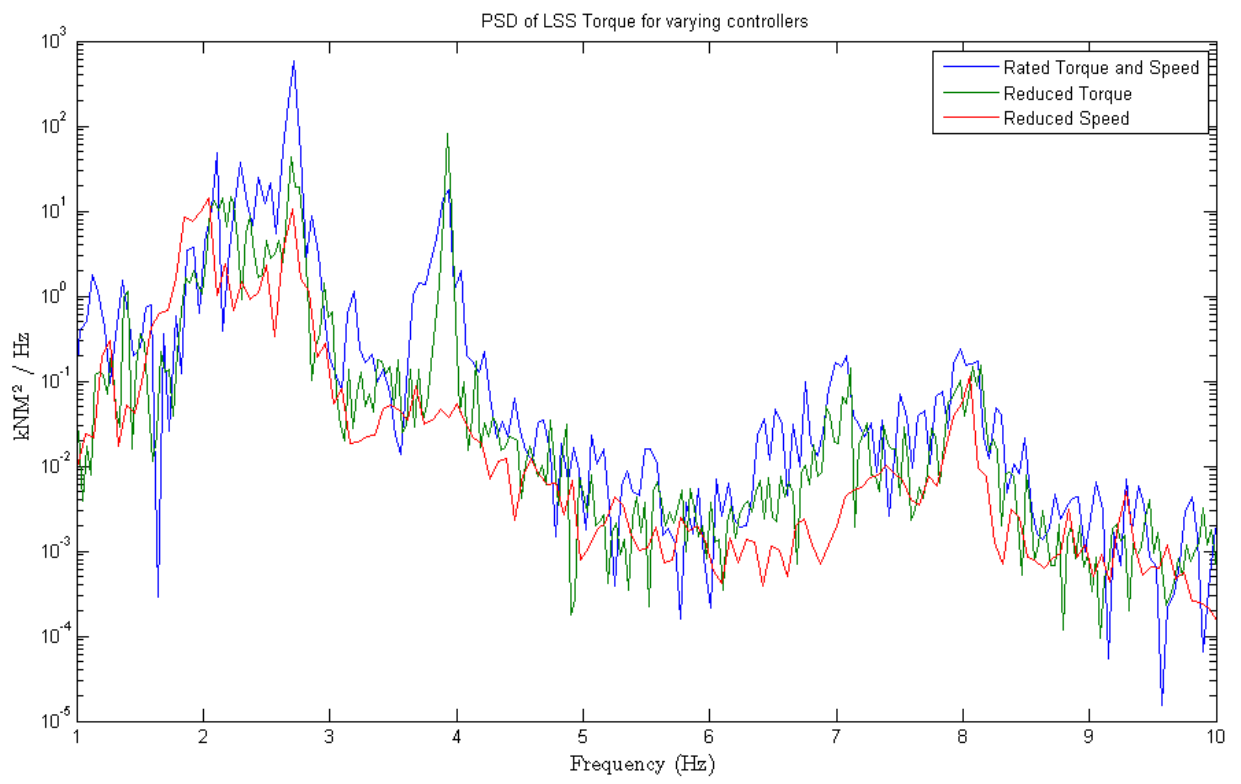

Figure 12. Comparing the PSD of LSS torque for various control options

Because reducing the rated speed of the turbine is successful in eliminating the $4 \mathrm{~Hz}$ oscillation and the instability at $2.7 \mathrm{~Hz}$, the CART3 is now able to run at least in this configuration. However, it is not known at this point whether the PE behavior observed is a fundamental limitation of the drive or can be ameliorated. This work continues.

\section{Conclusion}

The CART3 is intended to be a wind turbine test bed for advanced controls research. In this paper, the CART3 turbine was presented and the theory behind its implementation was introduced. Further, investigation of vibrations discovered after the conversion of the CART3 from two to three blades, was presented as a "lessons learned" document. The use of waterfall plots in investigating these phenomena was explained and their usefulness in the investigations was illustrated. Finally, an example of wind-turbine instability was investigated and numerous known possibilities considered.

\section{Acknowledgements}

The authors would like to thank the following people whose help was pivotal in this work. Jim Adams, Don Baker, Gunjit Bir, Marshall Buhl, Denise Fisher, Rob Goldhor, Jerry Hur, Garth Johnson, Jason Jonkman, Neil Kelly, Ed Muljadi, Syhoune Thao, Paul Veers, and Scott Wilde of the National Wind Technology Center. Ervin Bossanyi of GL Garrad Hassan. Kathryn Johnson of Colorado School of Mines. Bernard Bulder of ECN. Daniel Blais of Rockwell Automation. 


\section{References}

${ }^{1}$ Laks, J., Pao, L. Y., Wright, A., Kelley, N., and Jonkman, B., "Blade Pitch Control with Preview Wind Measurements," 48th AIAA Aerospace Sciences Meeting, 2010.

${ }^{2}$ van Wingerden, J. W., Hulskamp, A., Barlas, T., Marrant, B., Van Kuik, G. A. M., Molenaar, D.-P., and Verhaegen, M., "On the proof of concept of a 'smart' wind turbine rotor blade for load alleviation," Wind Energy, Vol. 11, No. 3, 2008, pp. 265-280.

${ }^{3}$ Jonkman, J. M., "Influence of Control on the Pitch Damping of a Floating Wind Turbine," ASME Wind Energy Symposium, 2008.

${ }^{4}$ Miller, N. W. and Clark, K., "Advanced Controls Enable Wind Plants to Provide Ancillary Services," IEEE Power and Energy Society General Meeting, July 2010.

${ }^{5}$ Johnson, K. E. and Fingersh, L. J., "Adaptive Pitch Control of Variable-Speed Wind Turbines," Journal of Solar Energy Engineering, Vol. 130, No. 3, 2008, pp. 031012.

${ }^{6}$ Wright, A. D., Fingersh, L. J., and Stol, K. A., "Testing Further Controls to Mitigate Loads in the Controls Advanced Research Turbine," 48th AIAA Aerospace Sciences Meeting, 2010.

${ }^{7}$ Bossanyi, E. A., Wright, A. D., and Fleming, P. A., "Further progress with field testing of individual pitch control," European Wind Energy Conference, 2010.

${ }^{8}$ Lindenburg, C., "Aeroelastic Modelling of the LMH64.5 Blade, Dowec report No. DOWEC-02-KL-083/0," Tech. rep., 2002

${ }^{9}$ Hansen, M. H. and Buhl, T., "Design guidelines for passive instability suppression-Task-11 report, Ris report No. Ris-R-1775(EN)," Tech. rep., Ris, 2006.

${ }^{10}$ Jonkman, J. M. and Buhl, M. L., "FAST Manual User's Guide, NREL report No. NREL/EL-500-38230," Tech. rep., NREL, August 2005.

${ }^{11}$ Osgood, R., Bir, G., Mutha, H., Peeters, B., Luczak, M., and Sablon, G., "Full-scale modal wind turbine tests: comparing shaker excitation with wind excitation," Tech. rep., National Rewewable Energy Laboratory, 2009.

12 van Wingerden, J. W., Control of Wind Turbines with Smart Rotors: Proof of Concept ES LPV Subspace Identification, Ph.D. thesis, Delft University of Technology, 2008. 